CUPAUAM. 16-1989, 233-244

\title{
MATERIALES DE LA II EDAD DEL HIERRO PROCEDENTES DE EL ESPARTAL (MADRID)
}

\author{
JOAQUIN BARRIO \\ Ma CONCEPCION BlasCO
}

\section{Resumen}

En este artículo se presenta el hallazgo producido en un posible conjunto tumbal en el Espartal (Madrid). Se trata de un mango de hueso trabajado y de un plato de barniz rojo. El primero está relacionado con la industria ósea desarrollada por grupos de la II Edad del Hierro de la Meseta Norte y el plato es un exponente de los influjos ibéricos en esta región de la submeseta sur.

\section{Summary}

This paper presents two newfindings in the possible cemetery area at El Espartal (Madrid). The first is a worked bone handle, and the second a red burnished dish. The bone handle can the related to bone manufactures fron works hops of the Second Iron Age in the Northern Meseta. The dish reflects Iberian influence in this area of Southern Meseta.

El hallazgo de este pequeño lote de materiales lo realizó la Dra. Ma Angeles Alonso con motivo de la excavación de la necrópolis medieval del Cerro de Las Losas cuando se intentaba buscar en un punto cercano el poblado de ésta. Desde estas líneas agradecemos sinceramente haber puesto a nuestra disposición estos materiales para su estudio. Sirva, además, este pequeño trabajo como homenaje a su labor y a su persona. Las circunstancias de su localización las tomamos directamente del texto de dicha autora: "A un nivel de -0'70 mts apareció una capa de tierra arcillosa con manchas negruzcas que evidencia la presencia de fuego. Una serie de cantos rodados cuyo tamaño oscilaba entre $20 \mathrm{~cm}$. y $7 \mathrm{~cm}$., aparecieron dispuestos en óvalo, cuyo eje mayor, según la dirección norte-sur rodeaba un espacio de 0'75 mts por 0'33 m., en el que hallamos, envueltos en cenizas, una serie de fragmentos cerámicos...”. (Alonso 1976, p. 311).

El yacimiento se halla ubicado en una de las terrazas por encima del curso del río Jarama, y responde dentro de la Hoja 509 (Torrelaguna) del IGC a las siguientes coordenadas: 331 ' 50 " Oeste. $4045^{\prime} 07$ " Norte. $680 \mathrm{~m}$. de altitud (Fig. 1). 


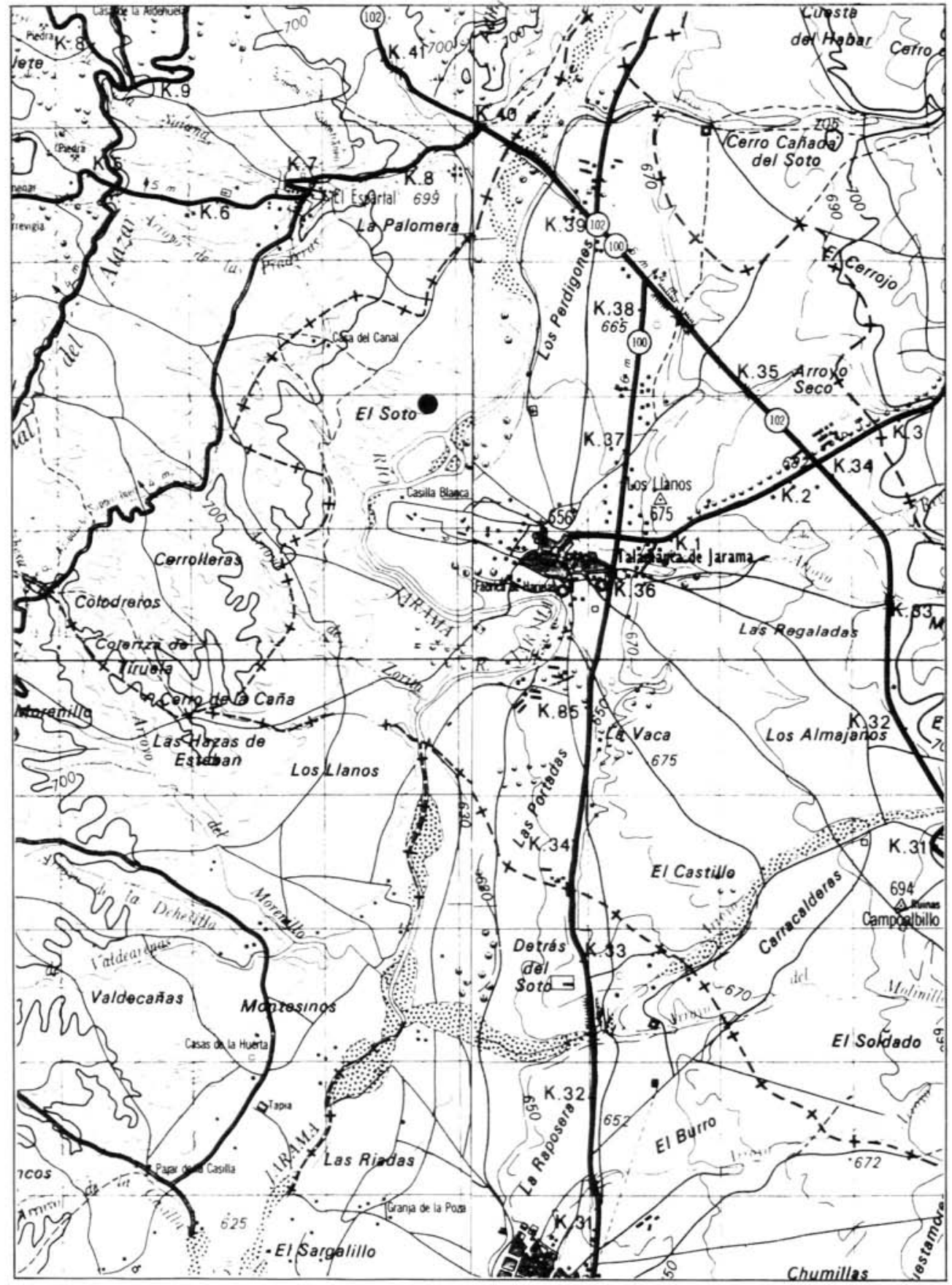

Figura 1. Localización del yacimiento. Hojas 509/510. IGC. 
Comarcalmente se integra en la denominada comarca I (Lozoya-Sierra), en un área típica de tránsito entre la Sierra y la llanura de la Depresión del Tajo, con una climatología de temperaturas medias anuales en torno a los $15^{\circ}$ calificable como Mediterráneo templado húmedo, donde los meses libres de heladas pueden llegar a seis. El enclave de este yacimiento muestra una geología del Cuaternario en la zona del valle del Jarama y de tierras oligocenas en su parte más septentrional, con una litología habitual de arcosas. Todo ello hace que en estas llanuras aluviales conformadas por recientes aluviones cuaternarios hayan persistido suelos profundos, bien aireados, con alto potencial productivo para el cultivo de cereales en secano mediante labor intensiva y para el aprovechamiento de los pastizales crecidos en la misma línea del río. En resumen, una zona de una potencialidad agroclimatológica dentro de la Llanura de tipo medio/alto, elevada por la inmediatez del eje fluvial, convirtiéndose por ello en terreno preferencial y muy apropiado para el desarrollo de la típica economía agropecuaria de los pueblos prerromanos ubicados en el interior peninsular. (M.C.A. 1985, pp. 8-28).

La primera de las piezas del hallazgo es una cerámica de pasta rojiza con forma de plato de borde exvasado y marcado por una pequeña carena, cuyas medidas son: $176 \mathrm{mms}$. de diámetro y una altura máxima de $39 \mathrm{mms}$. Aunque le falta la base hemos supuesto que se trataba de un pequeño pie anular, tomando como referencia los paralelos encontrados (Fig. 2).

En lo referente a las características técnicas de estas pastas de piezas de barniz rojo aparecidas en las tierras del interior, contamos con un análisis puntual en el yacimiento de Barchín del Hoyo (Cuenca) (Sierra, 1981, pp.243-244), cuyos datos pueden ser indicativos para nuestro caso. De su estudio se puede desprender la siguiente valoración: estructura vítrea interna de escasa porosidad como señal de una temperatura de cocción en torno a los $1000^{\circ}$, porcentajes altos de $\mathrm{FeO}(9 / 10 \%)$ y de $\mathrm{CaO}$ en la arcilla, y un barniz rojo donde estos niveles de Oxido de Hierro se elevan hasta el 16,56\%, como muestra de que la arcilla utilizada para confeccionar éste era muy rica en hematites.

Por lo que compete al análisis de las características formales del plato, su relación entre la anchura del borde $(22 \mathrm{mms}$ ) y el diámetro del vaso $(176 \mathrm{mms})$ es de 8 (González Prats, 1983, p.96).

Los restos de barniz, apenas visibles en el plato, son de un color rojo oscuro sin rastros de vitrificación, corresponde, por tanto, a la variante de barniz, tipo III, de las definidas por Cuadrado (Cuadrado, 1969, p. 262) que, en opinión de este autor, "aparece en vajillas de los ajuares ibéricos". Por otra parte la forma corresponde al tipo II del denominado grupo "ibero-tartesio" (Cuadrado, 1969, p. 267), sin que sea posible precisar a cuál de las dos variantes pertenece por faltarle el fondo, si bien existen indicios para pensar que debió de tener un pequeño pie.

Esta forma tiene una amplia distribución en la submeseta sur, al ser una de las morfologías que se asocian con cierta frecuencia a las primeras producciones a torno que aparecen en esta zona, no obstante en estos primeros momentos se asocia a ejemplares cerámicos de cocción reductora. Entre los yacimientos en los que se documenta este plato en tonos grises cabe citar las necrópolis conquenses de El Navazo (Galán, 1980) y Las Madrigueras (Almagro, 1969), donde aparecen como tapaderas de urnas realizadas a mano o a torno. Concretamente en el segundo de los conjuntos citados corresponde al tipo I de la tabla confeccionada para recipientes grises a torno y tiene una importante similitud con la forma 2, de la tabla IX, perteneciente a la cerámica de "tipo ibérico" (Almagro, 1969). Si la tumba de El Navazo en la que aparece este tipo de plato se ha fechado en torno al siglo $\mathrm{V}$ por la existencia de una fíbula de bucle, en Las Madrigueras aparecen en sepulturas datables en el siglo IV. 

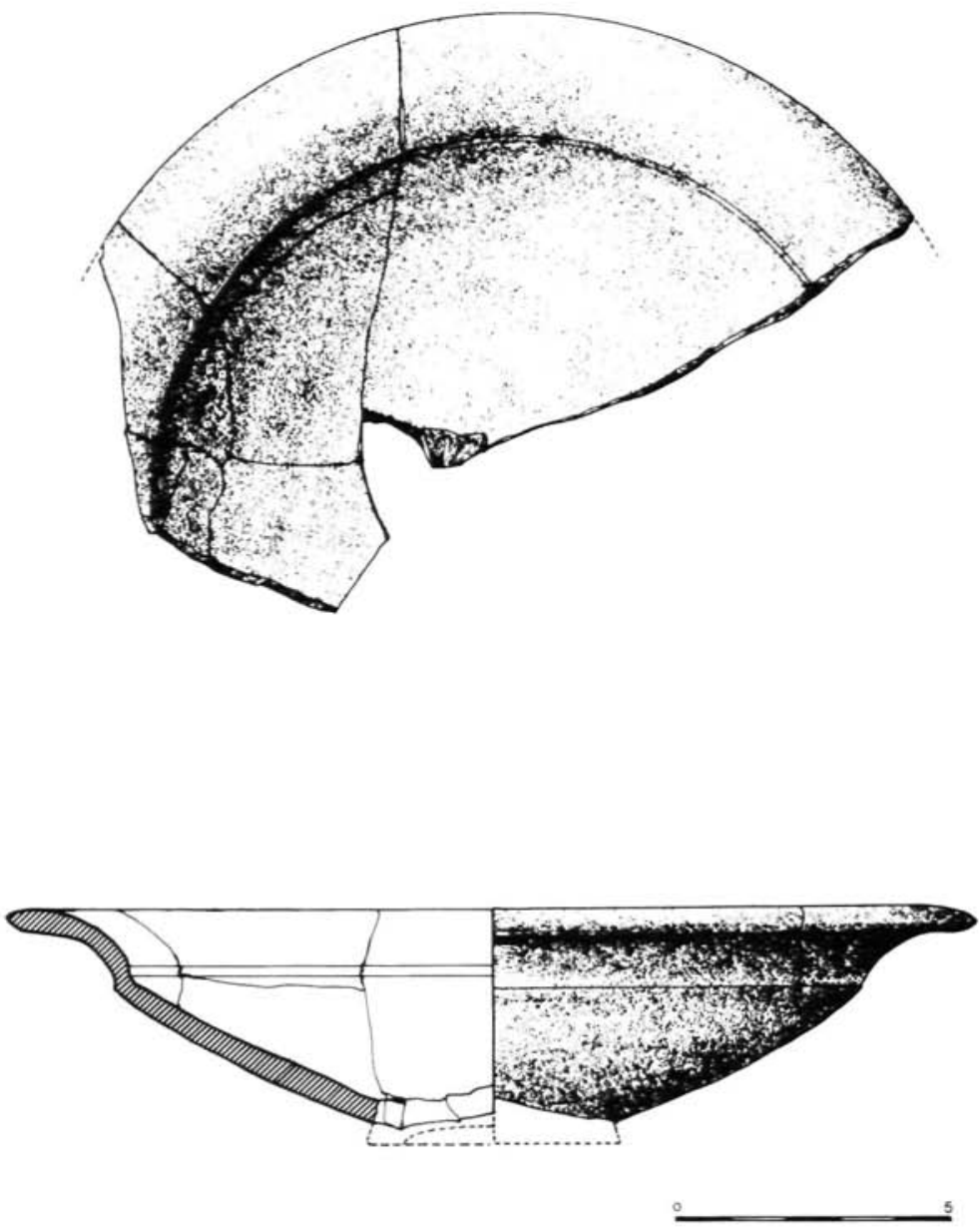

Figura 2. Plato de cerámica de barniz rojo.

Un tercer yacimiento en el que encontramos platos grises de esta morfología es el Cerro de los Encaños (Gómez, 1986, fig.17, p. 307), en este caso se trata de un poblado con dos niveles fechados entre los siglos VI y IV a.C. y donde la forma que nos ocupa está presente en los dos momentos de ocupación del habitat, no obstante, la fecha para el momento inicial del asentamiento en el que ya aparece la cerámica a torno se ha considerado excesivamente alta y la mayoría de los autores la aceptan con ciertas precauciones. Otro poblado conquense, Cabeza Moya, ha ofrecido también este mismo tipo de platos grises asociados a unos materiales a los que se les ha adjudicado una datación entre inicios del siglo V y fines del III a. C. (Navarro y Sandoval, 1984 , p. 289 y fig. 36 en p. 242), momento en el se encuadran un importante número de yacimientos ibéricos de la submeseta sur. 
Igualmente frecuentes en la submeseta sur son los platos de esta morfología con decoración pintada de tipo ibérico que son recogidos por P. Mena en su forma III (Mena, 1984, p. 114) y que, como los grises, aparecen tanto en necrópolis, como es el caso de la ya citada de Las Madrigueras, como en poblados. Un ejemplo de habitat donde está representado este plato con decoración pintada es Fuente Mota (Sierra, 1981, p. 267, fig. 25) fechado por C14 a inicios del s. IV, datación que coincide con la tumba de Las Madrigueras que proporcionó este mismo tipo de plato asociado a pintura de tipo ibérico.

En el entorno más próximo al hallazgo que nos ocupa, en la misma provincia de Madrid y dentro de la propia cuenca del río Jarama, a sólo unos $8 \mathrm{kms}$ aguas abajo, se ha documentado también esta forma en el yacimiento de Cerro Redondo, en Fuente el Saz del Jarama (Blasco y Alonso, 1985, p. 96, fig. 34, 13), corresponde a un plato a torno de superficie gris recuperado en el nivel III, el más antiguo del habitat y cuya cronología hay que situarla en el tránsito de los siglos $\mathrm{V}$ a IV antes de Cristo, una datación en la que parecen abundar este tipo de recipientes en las tierras orientales de la Submeseta sur.

Si habitual es en el área de la Submeseta sur la forma de la pieza que nos ocupa, no menos frecuente es el acabado de barniz o engobe rojo, un tratamiento que, durante algún tiempo se había identificado con el ámbito más próximo a las colonias fenicias del que la Meseta quedaba excluída, a excepción de las tierras más próximas al sudeste, en cuyo caso se encontraba el yacimiento albaceteño de El Macalón en el límite con la provincia de Murcia. La posterior identificación de este tratamiento en yacimientos ubicados más al interior, como es el caso de Las Madrigueras (Carrascosa del Campo), en Cuenca o Villanueva de Bogas (Toledo) se explicó por vía de un comercio interior (Cuadrado, 1969, p. 285).

Pero pronto, a los primeros hallazgos de cerámica de barniz rojo en tierras de la submeseta sur, producidos a fines de los años 60 , han seguido un considerable número que actualmente suman cerca de treinta yacimientos (Fernández Rodríguez, 1988, p. 316), algunos de los cuales, como el de Alarcos han proporcionado 647 fragmentos. Este hecho obliga a replantear la hipótesis que explica la presencia de esta variedad alfarera por vía comercial, frente a una posible elaboración local o, al menos, a considerar la doble posibilidad, pues las características y las proporciones de este tipo de barniz resulta bastante dispar (Fig. 3).

Así, en el caso de Alarcos, único yacimiento meseteño en el que esta variedad alfarera ha merecido un estudio monográfico, los fragmentos que presentan algún tipo de barniz rojo suponen el 3'5 \% del total de los hallazgos cerámicos de los niveles en que se encuentran (Fernández Rodríguez; 1987, p. 87). Desgraciadamente, no contamos con otros estudios monográficos como el de Alarcos que nos permitan conocer si el volumen de piezas con engobe o barniz rojo es similar o, por el contrario, nos encontramos con un caso excepcional que afecta a este yacimiento o, en todo caso, a conjuntos del área más meridional de la Meseta, entre los que podría incluirse Oreto y el Cerro de Las Cabezas donde todo parece indicar que esta variedad es también relativamente importante. Por el contrario, en los habitats de zonas más septentrionales, como pueden ser el Cerrón (Illescas, Toledo), Fuente de la Mota (Barchín del Hoyo, Cuenca) o Cerro Redondo (Fuente el Saz, Madrid), que cuentan con un importante volumen de materiales publicados, han ofrecido muy escasos fragmentos con engobe o barniz rojo, encontrándose en una proporción similar a las cerámicas áticas.

A falta de estudios más detallados, cabría plantearse que buena parte de la Oretania que engloba la cuenca del Guadiana podría quedar dentro del área de fabricación de esta cerámica de engobe de producción peninsular denominada ibero-tartesia, de igual manera que se incluyó, 
desde un principio a las tierras más sudorientales de Albacete. En cambio, es posible que al resto de regiones de la submeseta sur llegue por vía comercial, a través de unos circuitos que seguramente comercializan también otras piezas de importación como son las cerámicas áticas.

No nos hemos referido a las necrópolis a pesar de que constituyen la mayor parte de los yacimientos que cartografiamos (Fig. 1), ya que en ellas se produce una evidente selección del material y en consecuencia las proporciones de los diferentes tipos cerámicos son muy distintas a los conjuntos domésticos, al ser más importante la presencia de materiales exóticos entre los que se incluyen las cerámicas de importación. De todas formas, también este tipo de yacimientos nos proporciona un dato de interés como es la coincidencia del barniz rojo y la cerámica ática que vendría a confirmar la existencia de un mismo mecanismo de distribución de materiales de importación con distintas procedencias de origen.

La segunda de las piezas del conjunto es un mango (187 cms de largo, $11 \mathrm{cms}$ de diámetro) posiblemente confeccionado en un hueso de ovicáprido, que sirvió como elemento para encajar en su interior un útil de hierro (punzón, estilete, cuchillo, ..), puesto que en su extremo distal, del cual ha perdido una parte, aún queda embutida la espiga de éste. Al estar recortado de la diáfisis de un hueso de sección anular presenta una perforación completa por ambos lados. Con una simple observación visual se reconocen algunos detalles de las técnicas de trabajo que han intervenido en su cuidada realización: limado y pulimento exterior, regularización del vaciado interior (Fig. 4).

En cuanto a los rasgos de su interesante decoración, en ambos extremos presenta una serie de cinco finas incisiones que componen una banda, mientras que en el centro de la pieza esta misma técnica de la incisión define una banda más ancha en retícula enmarcada entre sendas líneas.

A la hora de enmarcar la tipología de este elemento de hueso en la series definidas tanto por Rodanés -Tipo XXIX- (Rodanés, 1987), dedicado a los períodos neolíticos y del Bronce dentro del Valle del Ebro, como a la más cercana cronológicamente de Liseau para la II Edad del Hierro en el yacimiento de la II Edad del Hierro de Soto de Medinilla (Liseau, 1988, pp.183-213), es preciso englobarlo en el grupo de "diversos", y dentro de éste en el tipo 3 de Mangos ("mangos de forma cilíndrica con el extremo proximal abierto o cerrado.."). En relación con los tipos definidos para este período prerromano en Segovia quedaría enmarcado en el Tipo IV.b (Barrio, 1989, pp.857-869).

Correspondería, pues, a una de esas piezas calificadas de "pasivas" y cuya relación sólo se entiende a partir de la necesidad que otros objetos de metal tienen de ellas. Algunos de estos mangos que debieron de servir para pequeños cuchillos o punzones que aparecen tanto en poblados como en necrópolis de las Mesetas Sur y Norte en su inmediato período prerromano. Sin embargo, a grandes rasgos nuestra pieza de hueso respondería más a esa tónica general en la aparición de dichos objetos, que muestra un mayor porcentaje de mangos de cuidada elaboración en las necrópolis frente a los poblados, donde por el contrario se observa la presencia de un número más abundante de piezas en asta de ciervo apenas sin elaborar, dedicadas al enmangue de herramientas de trabajo (hoces, podones, escoplos, ...). Esta es la conclusión inical a la que creemos puede llegarse desde un análisis de la industria ósea de esta época.

Por otra parte, si bien este elemento de la industria del hueso no es susceptible de permitirnos un encaje cronológico de cierta precisión, por sus caracteres técnicos y tipológicos se puede enmarcar sin problemas en los límites definidos por el plato de "barniz rojo" que se integra en este mismo conjunto funerario. Los paralelos con los que contamos para su análisis tanto en la Meseta Sur, muy escasos, como los más numerosos de la Meseta Norte, apuntarian en este sentido. 


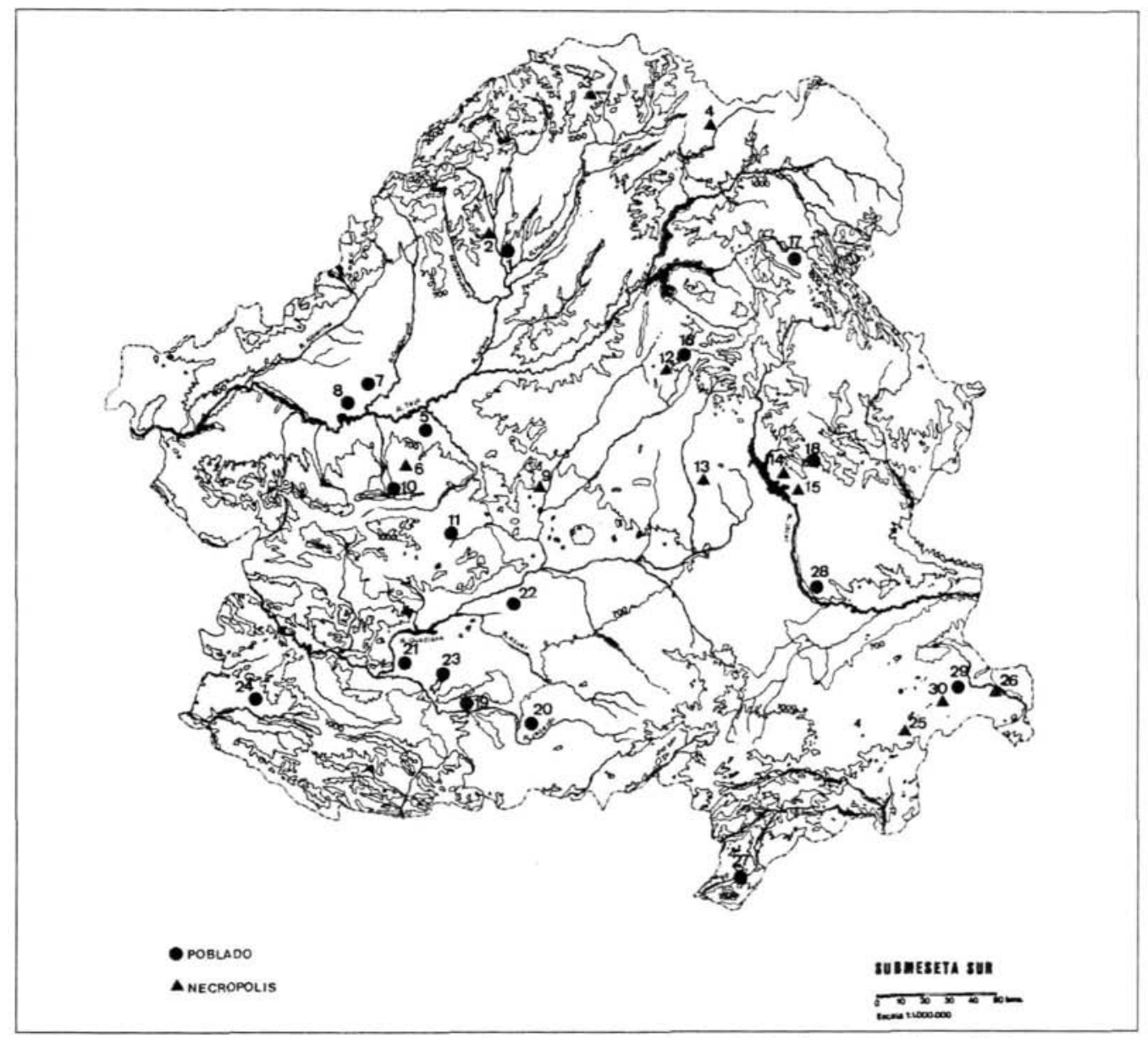

Figura 3. Mapa de dispersión de barniz rojo en la Submeseta Sur. Según Fernández Rodríguez (1988), ampliado por autores.

MADRID

1. Cerro Redondo.

2. El Espartal.

TOLEDO

5. Ocaña.

6. Villanueva de Bogas.

7. Yeles.

8. El Cerrón. Illescas.

9. Palomar del Píntado.

10. Cerro del Castillo.

11. Cerro del Calderico.
CIUDAD REAL

19. Oreto.

20. Cerro de las Cabezas.

21. Alarcos.

22. Casa Quemada.

23. Las Cagillas.

24. La Bienvenida.

GUADALAJARA

3. Altillo de Cerropozo.

4. La Olmeda.

CUENCA

12. Las Madrigueras.

13. Alconchel.
14. Buenache de Alarcón.

15. Olmedilla de Alarcón.

16. Cerro de la Muela.

17. Canizares.

18. Fuente de la Mota.

\section{ALBACETE}

25. Hoya de Sta. Ana.

26. Llano de la Consolación

27. El Macal-n.

28. Abengibre.

29. El Amare-o.

30. Pozo Moro. 


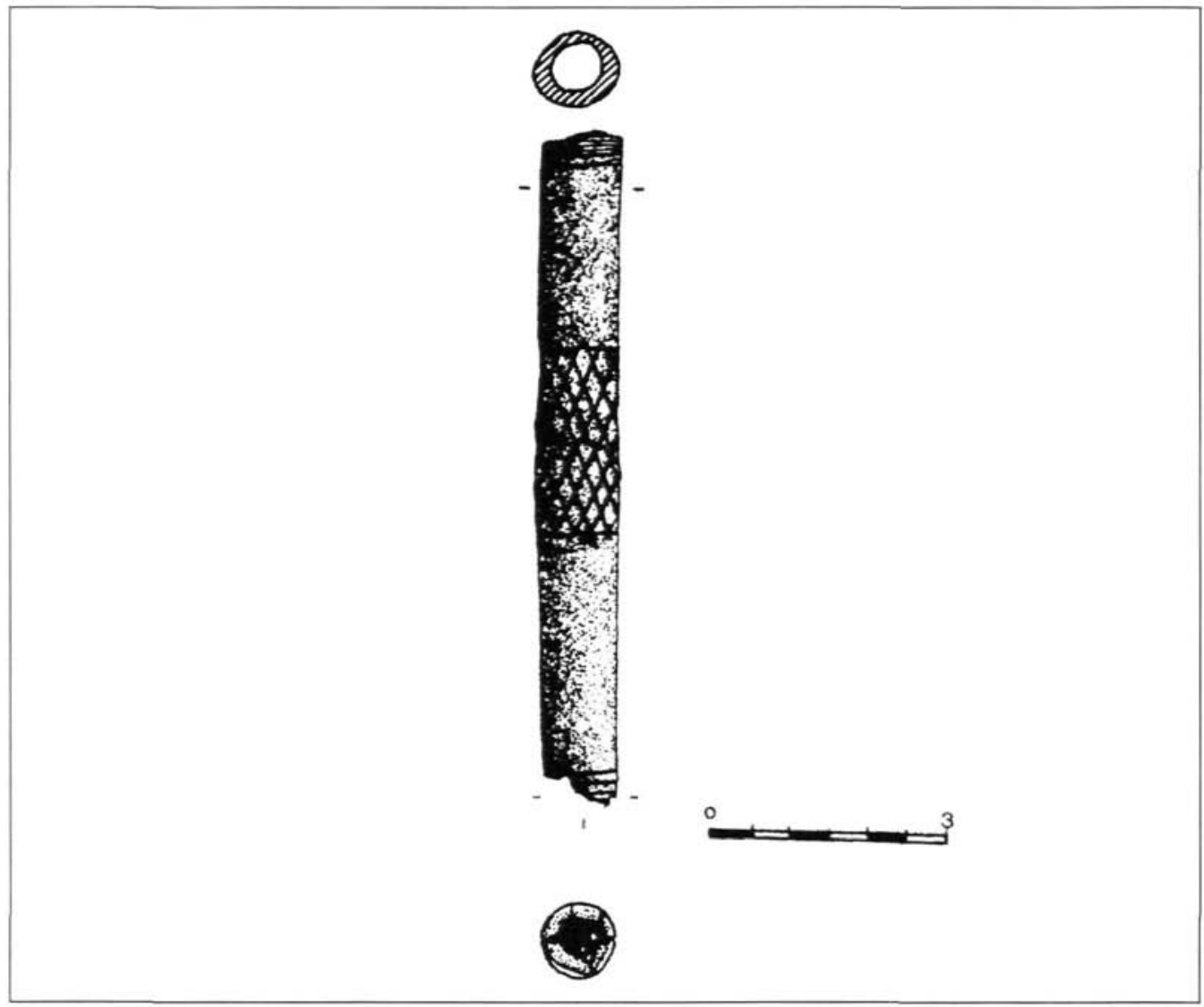

Figura 4. Mango de hueso decorado.

De este modo, en el contexto cultural de la II Edad del Hierro de las tierras del interior encontramos algunos elementos y temáticas decorativas relacionables con este pequeño mango de hueso.

En las estas tierras meridionales de la Meseta Sur, contamos con un excelente paralelo en el mango aparecido en la tumba XLV de la necrópolis de las Madrigueras (Almagro Gorbea, 1969, pp. 69-70; fig. 42, 5), donde incluso se recoge junto a un plato de pasta gris, pero de tipología similar al vaso de nuestra sepultura. Según este autor se localiza en el Estrato II, fechado entre 425-350 a.C.

Por su parte, en los yacimientos de esta poca en Meseta Norte, encontramos algún elemento de conexión en la necrópolis de Las Cogotas (Cabré 1932, pp.83, lám. LXXIX, 2), en una cacha de hueso con decoración de incisiones en reticulado. Pero son fundamentalmente los ejemplares aparecidos en las sepulturas 9 y 104 de la necrópolis de La Osera en un ambiente clásico de la II Edad del Hierro de la Meseta Norte, los que muestran un mayor parecido con esta pieza de El Espartal, al tratarse en ambos casos de pequeños mangos de hueso con decoración reticulada de finas incisiones en su parte central (Cabré et alii, 1950, p.197 y figs. 9-10). No es de extrañar esta conexión a través de ciertos materiales arqueológicos entre unos y otros yacimientos a 
ambos lados del Sistema Central, como ya se puso de manifiesto con algunas cerámicas a peine localizadas en el cercano asentamiento de Cerro Redondo (Fuente el Saz de Jarama), y que recientemente han aparecido también en mayor número en la necrópolis toledana de Las Esperillas (García/Encinas, 1990, pp.317-326). Además, esta ruta natural del Jarama, bien a través de este río bien a través del valle del afluente Lozoya, lleva a una comunicación directa con las tierras de la Meseta Norte.

Además de los citados, es posible tener en cuenta otros puntos con industria ósea relacionable de tanto interés como el poblado celtibérico de El Soto de Medinilla (ESCUDERO, 1988, pp. 38-39); Langa de Duero (Taracena, 1929, pp.49-50), y sobre todo Numancia, donde sobresale un conjunto de carácter excepcional de estas manufacturas óseas y una especial conexión muestra la decoración de nuestro mango con unas varillas con incisiones en "espina de pescado" (Taracena/Mélida 1921, pp.7-8; láms. VI-VII).

Por otra parte, esta decoración de reticulados muy simples se puede comporabar con abundancia numerosas cerámicas con temas de "peine" en la Meseta Norte o en vasos pintados a mano con pintura postcocción como, por ejemplo, los localizados en la referida necrópolis de las Madrigueras.

En definitiva, este pequeño mango de hueso constataría la evidencia de la imposición generalizada de los útiles "pasivos" (cachas, mangos, ...), frente a los "activos" (agujas, punzones, perforadores, ...), relegándose la industria ósea durante la II Edad del Hierro al cumplimiento de un papel subsidiario en relación con la metalurgia tanto del bronce, como fundamentalmente del hierro.

En suma, estos materiales: plato de barniz rojo y mango de hueso trabajado se encuadran no sólo en el marco de li II Edad del Hierro de la Submeseta sur, sino que también encajan perfectamente dentro del ambiente general de esta etapa en la región de Madrid donde, a pesar de que todavía son pocos los yacimientos conocidos y menos aún los estudiados con cierta profundidad, existen ya datos para poder esbozar un marco general y las principales corrientes culturales en las que está inmersa.

El yacimiento de referencia es Cerro Redondo, un pequeño caserío fechado entre los siglos $\mathrm{V}$ a III a. C. que ha proporcionado elementos significativos que permiten conocer los vectores dominantes de las relaciones de esta etapa, por una parte, con la Meseta Norte, por otra, con el área ibérica. Un panorama que parece reconocerse también en los otros yacimientos menos conocidos como son Cerro Butarrón, Titulcia, Cerro de la Gavia, Estación de Santa Catalina o el Cerro y la Cueva de Santa Catalina (Blasco y Alonso, 1983, p.128), así como en los castros de pie de monte de Santorcaz y Dehesa de la Oliva (Valiente, 1987, p. 126) aunque de ellos sólo tengamos noticias de las cerámicas que han brindado simples reconocimientos de superficie.

La importancia del hallazgo que nos ocupa es doble, en primer lugar por su procedencia de un posible conjunto funerario ya que los materiales aparecieron bajo una capa de tierra arcillosa con manchas negruzcas y dentro de un espacio ovalado creado por una serie de cantos rodados (Alonso, 1976, p. 311), conjunto que posiblemente haya que interpretarlo como los restos de una estructura tumular. Desgraciadamente la falta de una excavación ha impedido la confirmación de este supuesto y la realización de una pequeña cata de comprobación sería de sumo interés para confirmar este supuesto, sobre todo si se tiene en cuenta que no existe ninguna necrópolis ibérica documentada en esta región.

En efecto, hasta el momento sólo tenemos noticia de la existencia de hallazgos fortuitos de posibles tumbas en Titulcia, en las laderas del propio poblado; en el escarpe de uno de los cerros testigos de la margen izquierda del Manzanares junto al Cerro de San Antonio, o en Perales de 
Tajuña (Valiente, 1987, p. 130), de los que tan sólo conocemos algunos materiales muebles, sin relación con su contexto. La información que han proporcionado estos materiales apunta hacia un temprano desarrollo de las necrópolis no lejano a la cronología de los grandes conjuntos tumbales conquenses como el Navazo o Las Madrigueras, cuyo arranque parece estar ligado con la iberización de la zona ya que la mayoría de los materiales nos llevan a ese mundo, es el caso de las cerámicas pintadas o las fíbulas anulares. Sin embargo, no faltan tampoco algunas fíbulas de torrecilla, o las cerámicas grises, las cuales permitirían poner en relación estos yacimientos con las grandes necrópolis de Guadalajara o incluso con la Meseta Norte.

En segundo lugar, interesa destacar el significado de los dos objetos aquí estudiados: el mango de hueso decorado que parece guardar un importante paralelismo con la industria de este tipo desarrollada por los grupos del Hierro II de la Meseta Norte y por otra parte, el plato de barniz, un elemento que señala la importancia de la influencia que en este momento sigue teniendo el sudeste y, en general, el área ibérica en la totalidad de los grupos establecidos en la Submeseta sur.

Sin embargo, todos estos datos sólo nos permiten esbozar la indudable importancia de una etapa del territorio madrileño de la que, hasta el momento, lo desconocemos casi todo y a la que la homenajeada ha contribuído con su trabajo, a poner uno de sus primeros pilares. 


\section{BIBLIOGRAFIA}

Almagro Gorbea, M. 1969: La necrópolis de Las Madrigueras (Carrascosa del Campo), BPH nº X, Madrid.

... 1977: "La iberización de las zonas orientales de la Meseta", Symposium Internacional. Els origens del mon Iberic, Ampurias 38-40, Barcelona, pp. 93-157.

Alonso, A. 1976: "Necrópolis de "El Cerro de Las Losas" en El Espartal (Madrid), 1973", NAH. Arqueologia, 4. pp. 286-324.

Balmaseda, L.T. y Valiente, S. 1979: “Excavaciones en el Cerrón. Illescas, Toledo", NAH, n 7 , Madrid, pp. 153-210.

Barrio, J. 1989:La Segunda Edad del Hierro en Segovia, Tesis doctoral inédita defendida en la UAM, Madrid.

BLANQUEZ, J. 1990: La formación del mundo ibérico en el sureste de la Meseta. (Estudio arqueológico de las necrópolis ibéricas de la provincia de Albacete), Albacete.

Blasco, C. y Alonso, A. 1985: Cerro Redondo. Fuente el Saz del Jarama, Madrid, EAE, n 143, Madrid.

Broncano, S. y Blanquez, J. 1985: El Amarejo (Bonete, Albacete), EAE, no 139, Madrid.

CABRE, J. 1932: Excavaciones en Las Cogotas de Cardeñosa (Avila), Necrópolis, M.J.S.E.A, n 120.

CABRE, J. y otros 1950: El castro y la necrópolis del Hierro céltico de Chamartín de La Sierra (Avila) AAH, vol. V.

CuAdrado, E. 1969: "Origen y desarrollo de la cerámica de barniz rojo en el mundo tartésico", Tartessos y sus problemas. V Symposium Internacional de Prehistoria Peninsular, Jerez de la Frontera , 1969. Barcelona, pp. 257-291.

... 1971: "El Castro carpetano de Yeles (Toledo)", XII CAN Jaén, Zaragoza, pp. 355-362.

Escudero, Z. 1988: "El Soto de Medinilla”, Revista de Arqueologia, año IX, n89.pp. 32-41.

Fernandez Rodriguez, M.D. 1987: Alarcos. La cerámica de barniz rojo del Cerro de Alarcos, Ciudad Real.

... 1988: "Estado actual de la investigación de la cerámica de barniz rojo en Castilla-La Mancha", $1^{\circ}$ Congreso de Historia de Castilla-La Mancha, tomo III, Ciudad Real, pp. 309-318.

GaLAN, C. 1980: "Memoria de la primera campaña de excavaciones en la necrópolis de El Navazo. La Hinojosa (Cuenca)," NAH. no 8. pp. 141-212.

GarCla, A. y ENCINAS, M. 1990: "Cerámicas excisas del conjunto funerario de la necrópolis de Las Esperillas (Santa Cruz de la Zarza. Toledo)”, II Simposio sobre celtiberos. Necrópolis celtibéricas, Zaragoza, pp. 317-326.

Garcia Guinea, M.A. y San Miguel, J.A. 1965: "El poblado ibérico de "El Macalón", Albacete", $A E A, \mathrm{n}^{\circ} 25$.

Gomez RuIz, A. 1986: "El Cerro de Los Encaños (Villar del Horno, Cuenca)", NAH, n 27. pp. 265-350.

Gonzal.ez Prats, A. 1983: Estudio arqueológico del poblamiento antiguo de la Sierra de Crevillente (Alicante), Anejo I de la Revista Lucentum, Universidad de Alicante.

LifsSaU, C. 1990: "Estudio de la industria en asta de ciervo de El Soto de Medinilla", CuPAUAM, n 15 , pp. 183-213.

M.A.P.A. 1985: Mapa de cultivos y aprovechamientos de la provincia de Madrid, Madrid.

MENA, P. 1984: Catálogo de cerámicas de necrópolis de la Edad del Hierro del Museo de Cuenca, Boletín del Museo provincial de Cuenca, I. Cuenca.

... 1990: "Necrópolis de la Edad del Hierro en Cuenca", II Simposio sobre celtiberos, Necrópolis celtibéricas, Zaragoza, pp. 183-195. 
MiLLAN J.M. 1990: "Una necrópolis tumular en Cuenca:Alcaudel”, II Simposio sobre celtíberos. Necrópolis celtibéricas, Zaragoza. pp. 197-202.

Navarro, J. y Sandoval, C. 1984: “Cabeza Moya (Enguidanos, Cuenca). Primera y segunda campañas. Años 1980 y 1981”, NAH, n 19. pp. 199-270.

Negueruela, I. 1979-80: "Sobre la cerámica de engobe rojo en España", Habis, no 10-11, Sevilla, pp. 336-359.

Nieto, G., Sanchez Meseguer, J. y Poyato, C. 1980: Oreto I (Ciudad Real), EAE, no 114, Madrid.

RODANES, J. 1987: La industria ósea prehistórica en el Valle del Ebro. Neolitico y Edad del Bronce, D.G.A., Zaragoza.

Ruiz Zapatero, G. y CARROBles, J. 1986: "Una necrópolis tumular ibérica en La Mancha: Villafranca de Los Caballeros (Toledo)”, Revista de Arqueologia, año VII, n 66, Madrid, pp. 58-62.

Sierra, M. 1981: "Fuente de la Mota (Barchin del Hoyo-Cuenca)", NAH, no 11, Madrid, pp.209-307.

TARACENA, B. 1929: Excavaciones en las provincias de Soria y Logroño, M.J.S.E.A. no 103.

TARACENA, B. y MElidA, J. 1921: Excavaciones en Numancia, M.J.S.E.A., nº 36. 